\title{
Medium-term changes in Drosophila subobscura chromosomal inversion polymorphism: a possible relation with global warming?
}

\author{
GORAN ZIVANOVIC ${ }^{1 *}$, CONXITA ARENAS $^{2}$ and FRANCESC MESTRES ${ }^{3}$ \\ ${ }^{1}$ Department of Genetics, Institute for Biological Research Sinisa Stankovic, University of Belgrade, Belgrade 11000, Serbia \\ ${ }^{2}$ Departament d'Estadística, and ${ }^{3}$ Departament de Genètica, Universitat de Barcelona, Barcelona 08028, Spain
}

[Zivanovic G., Arenas C. and Mestres F. 2015 Medium-term changes in Drosophila subobscura chromosomal inversion polymorphism: a possible relation with global warming? J. Genet. 94, 343-346]

\section{Introduction}

Drosophila subobscura is a species with a rich chromosomal polymorphism for inversions. Evidence demonstrates that it is adaptive. In the present research, we studied whether it is possible to detect changes in the inversion chromosomal polymorphism of D. subobscura in a medium-term period of time. The Serbian population of Avala was selected and its inversion composition in 2004 and 2011 (a seven year period) was compared. Significant variation was found in the $\mathrm{U}$ chromosome. This result was due to a significant increase of $\mathrm{U}_{1+2}$ (warm) and a decrease of $\mathrm{U}_{\mathrm{st}}$ (cold) and $\mathrm{U}_{1+2+6}$. Further, minimum, maximum and mean temperatures increased (although not significantly). Thus, $\mathrm{U}$ chromosome seems to be able to react in a medium-term to temperature changes in the way expected by the global warming.

Karyotype of $D$. subobscura comprises five acrocentric $(\mathrm{X}=\mathrm{A}, \mathrm{E}, \mathrm{J}, \mathrm{O}, \mathrm{U})$ and one dot chromosomes, with $\mathrm{E}$ and $\mathrm{O}$ being the most polymorphic for inversions (Krimbas 1992, 1993). Although historic factors cannot be ruled out, it is generally accepted that this polymorphism is adaptive (for a revision, see Zivanovic et al. 2012; Pegueroles et al. 2013). It is well known that it varies seasonally (Fontdevila et al. 1983; Rodríguez-Trelles et al. 1996), and the same has been observed in Serbian populations (Zivanovic 2007; Zivanovic and Mestres 2010b). According to global warming expectations, long-term changes have been observed in this species (Orengo and Prevosti 1996; Rodriguez-Trelles and Rodriguez 1998; Solé et al. 2002; Balanya et al. 2004, 2006,2009 ). We have also reported this effect in several studies carried out in the Balkans (Zivanovic and Mestres 2010a, 2011; Zivanovic et al. 2012).

The aim of the present research was to assess whether in a medium-term period is it possible to detect changes in the

*For correspondence. E-mail: goranziv@ibiss.bg.ac.rs. inversion chromosomal polymorphism of D. subobscura. In a parallel way, variations in the following temperature measures, maximum, minimum and mean, have also been analysed. We studied Avala (Serbia) population of D. subobscura in 2004 and had the opportunity to collect flies again in 2011, exactly in the same location.

\section{Materials and methods}

D. subobscura flies were collected from Avala mountain (Serbia) population $\left(44^{\circ} 48^{\prime} \mathrm{N} 20^{\circ} 30^{\prime} \mathrm{E}\right)$, located at $18 \mathrm{~km}$ south of Belgrade. The physical and biological characteristics of the trapping place are described in Zivanovic and Mestres (2010b). Collections were obtained in 2004 (from $2^{\text {nd }}$ to $9^{\text {th }}$ of June) and in 2011 (from $30^{\text {th }}$ of May to $5^{\text {th }}$ of June), strictly in the same place. The second sample was obtained many days earlier because spring/summer has advanced $\sim 2.5$ days per decade in Europe (Menzel et al. 2006). Maximum, minimum and mean temperatures, and rainfall data were obtained from Republic Hydrometeorological Service (Serbia).

Wild males and one son of each wild female were individually crossed with virgin females of the Küsnacht strain, which is homokaryotypic for standard chromosomal arrangements in all five chromosomes (Zollinger 1950). Third instar larvae from the $F_{1}$ were dissected and polytene chromosomes were stained and squashed in aceto-orcein solution. For each cross, at least eight larvae were analysed. All crosses were carried out in individual vials with $25 \mathrm{~mL}$ standard corn-meal-sugar-agar-yeast medium maintained at $18^{\circ} \mathrm{C}, 60 \%$ relative humidity and $12 \mathrm{~h}$ light $/ 12 \mathrm{~h}$ dark cycle.

Fisher's exact test was used (statistically significant $P$ value $<0.05)$ to compare the chromosomal composition between 2004 and 2011. This test has been used since it is

Keywords. inversions; global warming; adaptation; Drosophila subobscura. 
more precise than chi-squared test when the expected frequencies are small. The corresponding $P$ values were obtained using the bootstrap procedure $(100,000$ runs). As described in Zivanovic et al. (2012), for analysing the temperature changes along years, a time series analyses was carried out. For all these computations, R package was used (http://CRAN.R-project.org).

\section{Results}

Inversion chromosomal polymorphisms from 2004 and 2011 samples are presented in table 1 . There were no significant differences for the A chromosome $(P=0.838), \mathrm{J}(P=1)$, $\mathrm{E}(P=0.569)$ and $\mathrm{O}(P=0.874)$. However, there were significant differences for the $\mathrm{U}$ chromosome $(P=0.008)$. Using the classification of Menozzi and Krimbas (1992) in 'cold' and 'warm' arrangements, $\mathrm{U}_{\mathrm{st}}$ (cold) showed a slight decrease $(P=0.417)$, but $\mathrm{U}_{\underline{1}+\underline{2}}$ (warm) showed a significant increase $(P=0.003)$, and the difference was significant even after Bonferroni correction. Finally, $\mathrm{U}_{\underline{1+2+6}}$ decreased

Table 1. Frequencies of chromosomal inversions from the Avala mountain population of D. subobscura, both in 2004 and 2011.

\begin{tabular}{|c|c|c|c|c|}
\hline \multirow[b]{2}{*}{ Chr inversion } & \multicolumn{2}{|c|}{2004} & \multicolumn{2}{|c|}{2011} \\
\hline & $n$ & $\%$ & $n$ & $\%$ \\
\hline $\mathrm{A}_{\text {st }}($ cold $)$ & 14 & 45.2 & 20 & 40.0 \\
\hline $\mathrm{A}_{1}($ cold $)$ & 9 & 29.0 & 18 & 36.0 \\
\hline $\mathrm{A}_{2}$ (warm) & 8 & 25.8 & 12 & 24.0 \\
\hline Total & 31 & & 50 & \\
\hline $\mathrm{J}_{\mathrm{st}}($ cold $)$ & 13 & 21.0 & 22 & 22.0 \\
\hline $\mathrm{J}_{1}$ (warm) & 49 & 79.0 & 78 & 78.0 \\
\hline Total & 62 & & 100 & \\
\hline $\mathrm{U}_{\mathrm{st}}($ cold $)$ & 8 & 12.9 & 8 & 8.0 \\
\hline $\mathrm{U}_{1}+\underline{2}$ (warm) & 20 & 32.2 & 57 & 57.0 \\
\hline $\mathrm{U}_{1+2+6}^{-}$ & 29 & 46.8 & 25 & 25.0 \\
\hline $\mathrm{U}_{1+8+\underline{2}}$ (warm) & 5 & 8.1 & 10 & 10.0 \\
\hline Total & 62 & & 100 & \\
\hline $\mathrm{E}_{\mathrm{st}}($ cold $)$ & 15 & 24.2 & 22 & 22.0 \\
\hline$E_{1+2}$ & 2 & 3.2 & 2 & 2.0 \\
\hline $\mathrm{E}_{1+2+9}($ warm $)$ & 31 & 50.0 & 45 & 45.0 \\
\hline $\mathrm{E}_{1+2+9}+12$ (warm) & - & - & 4 & 4.0 \\
\hline$E_{8}$ & 14 & 22.6 & 27 & 27.0 \\
\hline Total & 62 & & 100 & \\
\hline $\mathrm{O}_{\text {st }}($ cold $)$ & 12 & 17.1 & 18 & 18.0 \\
\hline $\mathrm{O}_{6}$ & 2 & 2.9 & - & - \\
\hline $\mathrm{O}_{3+4}$ (warm) & 33 & 47.2 & 44 & 44.0 \\
\hline $\mathrm{O}_{3+4}+\underline{1}$ (warm) & 7 & 10.0 & 11 & 11.0 \\
\hline $\mathrm{O}_{3+4}+2$ & - & - & 2 & 2.0 \\
\hline $\mathrm{O}_{3+4}+\overline{5}$ & 3 & 4.3 & 2 & 2.0 \\
\hline $\mathrm{O} \underline{3+4}+\underline{6}$ & 1 & 1.4 & 2 & 2.0 \\
\hline $\mathrm{O}_{3+4}+\overline{7}$ & 1 & 1.4 & 1 & 1.0 \\
\hline $\mathrm{O}_{3+4}+8$ (warm) & 3 & 4.3 & 7 & 7.0 \\
\hline $\mathrm{O}_{3+4+17}$ & - & - & 1 & 1.0 \\
\hline$\overline{\mathrm{O}} \overline{3+4}+\overline{22}$ & 8 & 11.4 & 12 & 12.0 \\
\hline Total & 70 & & 100 & \\
\hline
\end{tabular}

Inversions and arrangements are classified as 'cold-adapted' (cold) and 'warm-adapted' (warm) according to Menozzi and Krimbas (1992); $n$, number of chromosomes; -, absent.
Table 2. Meteorological data for the Avala mountain population for the month of June from 2004 to 2011.

\begin{tabular}{ccccc}
\hline Year & $T_{\text {max. }}\left({ }^{\circ} \mathrm{C}\right)$ & $T_{\text {min. }}\left({ }^{\circ} \mathrm{C}\right)$ & $T_{\text {mean }}\left({ }^{\circ} \mathrm{C}\right)$ & Rainfall (mm) \\
\hline 2004 & 25.3 & 15.1 & 19.9 & 113.3 \\
2005 & 24.5 & 14.8 & 19.6 & 107.1 \\
2006 & 24.2 & 15.6 & 19.8 & 127.1 \\
2007 & 28.4 & 17.7 & 23.0 & 59.6 \\
2008 & 27.4 & 17.5 & 22.2 & 84.6 \\
2009 & 25.1 & 15.6 & 20.1 & 150.6 \\
2010 & 25.0 & 16.2 & 20.5 & 172.1 \\
2011 & 26.7 & 16.5 & 21.3 & 43.2 \\
\hline
\end{tabular}

$T_{\text {max. }}$, maximum temperatures; $T_{\text {min. }}$, minimum temperature.

$(P=0.118)$ and $\mathrm{U}_{\underline{1+8}+\underline{2}}$ (warm) showed a negligible increase $(P=0.785)$. In general, the pattern of changes for the $\mathrm{U}$ chromosome agrees with the global warming expectations. As previously mentioned, changes over time were not significant for other chromosomes, but a qualitative observation allows us to conclude that no variation was present for the $\mathrm{A}$ and $\mathrm{J}$ chromosomes. Thus, comparing the variation in frequency of 'cold' inversions ( $A_{\text {st }}$ and $\left.A_{1}\right)$ with that of 'warm' inversion $\left(A_{2}\right)$, no changes were observed between 2004 and 2011. In the $\mathrm{J}$ chromosome, the only inversions observed ( $\mathrm{J}_{\mathrm{st}}$ classified as 'cold' and $\mathrm{J}_{1}$ considered 'warm') did not show any changes over the period of time analysed. Considering $\mathrm{E}$ chromosome, $\mathrm{E}_{\mathrm{st}}$ ('cold') showed a slight decrease $(P=0.848)$, but the 'warm' $\mathrm{E}_{1+2+9}$ also decreased $(P=$ 0.627). The 'warm' adapted $\mathrm{E}_{1+2+9+12}$ (not present in 2004) increased $(P=0.299)$. Finally for the $\mathrm{O}$ chromosome, $\mathrm{O}_{\mathrm{st}}$ ('cold') frequency slightly increased $(P=1)$, and among the 'warm' adapted, $\mathrm{O}_{3+4}$ decreased $(P=0.755)$, whereas $\mathrm{O}_{3+4+1}(P=1)$ and $\mathrm{O}_{3+4+8}(P=0.527)$ increased. Following Rego et al. (2010), we have tested whether there were differences between 'cold' and 'warm' groups of inversions in this seven year period. Analysing all chromosomes together or individually, in both conditions no significant variation was seen $(P=0.520$, when analysing all chromosomes) and individually: $\mathrm{A}(P=1), \mathrm{J}(P=1), \mathrm{E}(P=1), \mathrm{O}(P=1)$ and $\mathrm{U}(P=0.082)$.

Data regarding temperature and rainfall variations between 2004 and 2011 are shown in table 2. During this period, maximum temperature increased $\left(25.3\right.$ to $\left.26.7^{\circ} \mathrm{C}\right)$ and the same pattern was recorded for minimum (15.1 to $\left.16.5^{\circ} \mathrm{C}\right)$ and mean $\left(19.9\right.$ to $\left.21.3^{\circ} \mathrm{C}\right)$ temperatures. Although these measures of temperature showed an increasing trend, none of the changes were significant: maximum $(t=0.693$, $P=0.514)$, minimum $(t=1.256, P=0.256)$ and mean $(t=$ $0.876, P=0.415)$. Rainfall followed an erratic profile as expected under global warming conditions.

\section{Discussion}

In long-term studies, it has been observed that $D$. subobscura inversions change in frequency according to global warming 
expectations in three continents (Balanyà et al. 2006). For the medium-term study, our main result is that a significant change in frequency was observed for one of the chromosomes of $D$. subobscura karyotype. The significant variation for the $\mathrm{U}$ chromosome was found in a mediumterm period (seven years) and according to global warming expectations, because in this period, temperatures tend to increase. Likely, it was due to the significant increase of $\mathrm{U}_{1+\underline{2}}$ (warm) arrangement, whereas $\mathrm{U}_{1+2+6}$ clearly decreases. This later arrangement is considered to be not associated with temperature adaptation, but is characteristic of the Balkan region (Krimbas 1992, 1993). Additionally, another 'cold' adapted arrangement $\left(\mathrm{U}_{\mathrm{st}}\right)$ decreased and a 'warm' adapted one $\left(\mathrm{U}_{1+8+2}\right)$ increased, both in small proportion. Studying long-term changes, other authors have found significant variations for the $\mathrm{U}$ chromosome. Thus, De Frutos and Prevosti (1984), in a 21 years study and analysing different sites of the same locality (Tibidabo hill, near Barcelona) found significant changes for the $\mathrm{U}, \mathrm{A}, \mathrm{E}$ and $\mathrm{O}$ chromosomes. In the same place and continuing the previous research, Orengo and Prevosti (1996) found significant variations for the $U_{1+2}$ and $\mathrm{U}_{1+8+2}$ arrangements. In another long-term study, Solé et al. (2002) found a significant effect for the U chromosome in Montpellier (south of France) and Calvià (Majorca Island). In another long-term analysis using Atlantic and central Europe populations, significant differences in frequency for the $\mathrm{U}$ and $\mathrm{O}$ chromosomes were also detected (Balanyà et al. 2004). Finally in Balkans, Zivanovic and Mestres (2011) we found a significant variation for the U chromosome in Apatin (Serbia) population during 19942009. In this case, results were similar to those presented in the present research: $U_{\mathrm{st}}$ (cold) significantly decreased, $\mathrm{U}_{1+2}$ (warm) significantly increased and $\mathrm{U}_{1+8+2}$ (also considered 'warm') was found for the first time in this population. Similar results were found at Petnica (Serbia) for the period 19952010 (Zivanovic et al. 2012): $\mathrm{U}_{\text {st }}$ (cold) slightly decreased, $\mathrm{U}_{1+2+6}$ dramatically decreased, and $\mathrm{U}_{\underline{1+2}}$ and $\mathrm{U}_{\underline{1+8}+\underline{2}}$ (both considered 'warm') clearly increased.

We speculate that $U$ chromosome responds to medium and long-term changes because it presents a reduced number of arrangements in most studied populations. Further, the majority of these arrangements are associated with temperature. Maybe they do not react directly to temperature, but to an environmental factor linked to it. However, not all arrangements are adaptive to temperature. As mentioned previously, $\mathrm{U}_{1+2+6}$ is considered to be not related with thermal adaptation, but is rather frequent in the Balkan region and Asia Minor. In particular, environmental conditions of this region, it probably presents an adaptive advantage to their carriers. In the Balkans, it has also been observed to decrease in frequency over time in different studies (Zivanovic and Mestres 2011; Zivanovic et al. 2012), likely due to some kind of environmental changes. Thus, it seems that natural conditions are probably changing along the years in these populations and D. subobscura is adapting to them.

\section{Acknowledgements}

This study was supported by grant number 173025 from the Ministry of Education, Science and Technological Development of the Republic of Serbia, grant number CTM2013-48163-C2-2-R from the Ministerio de Economía y Competitividad (Spain) and 2014 SGR 336 and 2014 SGR 464 from the Generalitat de Catalunya (Spain). FM is member of the IRBio (Institut de Recerca de la Biodiversitat, Universitat de Barcelona).

\section{References}

Balanyà J., Solé E., Oller J. M., Sperlich D. and Serra L. 2004 Longterm changes in the chromosomal inversion polymorphism of Drosophila subobscura. II. European populations. J. Zool. Syst. Evol. Res. 42, 191-201.

Balanyà J., Oller J. M., Huey R. B., Gilchrist G. W. and Serra L. 2006 Global genetic change tracks global climate warming in Drosophila subobscura. Science 313, 1773-1775.

Balanyà J., Huey R. B., Gilchrist G. W. and Serra L. 2009 The chromosomal polymorphism of Drosophila subobscura: a micro evolutionary weapon to monitor global change. Heredity 103, 364 367.

De Frutos R. and Prevosti A. 1984 Temporal changes of chromosomal polymorphism in natural populations of Drosophila subobscura. Genetica 63, 181-187.

Fontdevila A., Zapata C., Alvarez G., Sanchez L., Méndez J. and Enriquez I. 1983 Genetic coadaptation in the chromosomal polymorphism of Drosophila subobscura. I. Seasonal changes of gametic disequilibrium in a natural population. Genetics $\mathbf{1 0 5}$, 935-955.

Krimbas C. B. 1992 The inversion polymorphism of Drosophila subobscura. In Drosophila inversion polymorphism (ed. C. B. Krimbas and J. R. Powell), pp. 127-220. CRC Press, Boca Raton, USA.

Krimbas C. B. 1993 Drosophila subobscura: biology, genetics and inversion polymorphism. Verlag Dr, Kovac, Hamburg.

Menozzi P. and Krimbas C. B. 1992 The inversion polymorphism of Drosophila subobscura revisited: synthetic maps of gene arrangements frequencies and their interpretation. J. Evol. Biol. 5, 625-641.

Menzel A., Sparks T. H., Estrella N., Koch E., Aasa A., Ahas R. et al. 2006 European phenological response to climate change matches the warming pattern. Global Change Biol. 12, 19691976.

Orengo D. J. and Prevosti A. 1996 Temporal changes in chromosomal polymorphism of Drosophila subobscura related to climatic changes. Evolution 50, 1346-1350.

Pegueroles C., Aquadro C. F., Mestres F. and Pascual M. 2013 Gene flow and gene flux shape evolutionary patterns of variation in Drosophila subobscura. Heredity 110, 502-529.

Rego C., Balanyà J., Fragata I., Matos M., Rezende E. L. and Santos M. 2010 Clinal patterns of chromosomal inversion polymorphism in Drosophila subobscura are partly associated with thermal preferences and heat stress resistance. Evolution 64, 385-397.

Rodríguez-Trelles F. and Rodríguez M. A. 1998 Rapid microevolution and loss of chromosomal diversity in Drosophila in response to climate warming. Evol. Ecol. 12, 829-838.

Rodríguez-Trelles F., Alvarez G. and Zapata C. 1996 Time-series analysis of seasonal changes of the $\mathrm{O}$ inversion polymorphism of Drosophila subobscura. Genetics 142, 179-187.

Solé E., Balanyà J., Sperlich D. and Serra L. 2002 Longterm changes in the chromosomal inversion polymorphism of Drosophila subobscura. I. Mediterranean populations from southwestern Europe. Evolution 56, 830-835. 
Zivanovic G. 2007 Seasonal changes in chromosomal inversion polymorphism in a Drosophila subobscura natural population from a Southeastern European continental refugium of the last glaciation period. Russ. J. Genet. 43, 1344-1349.

Zivanovic G. and Mestres F. 2010a Viabilities of Drosophila subobscura homo- and heterokaryotypes at optimal and stress temperatures. I. Analysis over several years. Hereditas 147, 7081.

Zivanovic G. and Mestres F. 2010b Viabilities of Drosophila subobscura homo- and heterokaryotypes at optimal and stress temperatures. II. Seasonal component analysis. Hereditas 147, 8289.
Zivanovic G. and Mestres F. 2011 Changes in chromosomal polymorphism and global warming: the case of Drosophila subobscura from Apatin (Serbia). Genet. Mol. Biol. 34, 489495.

Zivanovic G., Arenas C. and Mestres F. 2012 Short- and long-term changes in chromosomal inversion polymorphism and global warming: Drosophila subobscura from the Balkans. Isr. J. Ecol. Evol. 58, 289-311.

Zollinger E. 1950 Ein strukturell homozygoter Stamm von Drosophila subobscura aus einer Wildpopulation. Arch. Julius Klaus-Stift. Vererbungsforsch. Sozialanthropol. Rassenhyg. 25, 33-35.

Received 18 September 2014, in final revised form 23 January 2015; accepted 30 January 2015

Final version published online: 2 June 2015 